\begin{tabular}{|l|l|l||}
\hline \multicolumn{2}{|c|}{ PublisherInfo } \\
\hline \hline PublisherName & $:$ & BioMed Central \\
\hline \hline PublisherLocation & $:$ & London \\
\hline \hline PublisherImprintName & $:$ & BioMed Central \\
\hline \hline
\end{tabular}

\title{
Comparison of five sedation scoring systems by means of auditory evoked potentials
}

\begin{tabular}{||l|l|l||}
\hline \multicolumn{2}{|c||}{ ArticleInfo } \\
\hline \hline ArticleID & $:$ & 4078 \\
\hline \hline ArticleDOI & $:$ & $10.1186 /$ ccf-1999-121 \\
\hline \hline ArticleCitationID & $:$ & 121 \\
\hline \hline ArticleSequenceNumber & $:$ & 15 \\
\hline \hline ArticleCategory & $:$ & Paper Report \\
\hline \hline ArticleFirstPage & $:$ & 1 \\
\hline \hline ArticleLastPage & $:$ & 4 \\
\hline \hline & & RegistrationDate : 1999-5-7 \\
ArticleHistory & $:$ & OnlineDate $\quad$ 1999-5-7 \\
\hline \hline ArticleCopyright & $:$ & Current Science Ltd1999 \\
\hline \hline ArticleGrants & $:$ & \\
\hline \hline ArticleContext & $:$ & 130541111 \\
\hline \hline
\end{tabular}




\section{Keywords}

Evoked potentials, intensive care therapy, monitoring of sedation, sedation, sedation score

\section{Comments}

The drawbacks of AERs are that they require training and experience, and the effects of repeated auditory stimuli on a critically ill patient are unknown. The newer bispectral index monitor may be more useful in the ICU setting since it is simple to use by all staff and requires no auditory input. Alternatively in the absence of these expensive monitoring systems, oversedation may be avoided by switching off sedation at regular periods and not restarting infusions until the patient reaches a lesser sedation score.

\section{Introduction}

Auditory evoked responses (AEP) have been used as a means of monitoring awareness during anaesthesia. Attention has focused on the latency of the early cortical response $\mathrm{N}_{b}$ which indicates light anaesthesia and potential awareness when decreased to less than $44.5 \mathrm{~ms}$. On the intensive care unit (ICU) sedation and analgesia is necessary to prevent ventilator dysynchrony and allow unpleasant procedures to take place. Sedation scoring systems are usually used to assess the level of sedation but unfortunately they are subjective and poor indicators of oversedation.

\section{Aims}

The authors have compared an objective measure (AER) with various subjective scoring systems.

\section{Methods}

The study investigated 95 consecutive patients requiring sedation for ventilation on the ICU. Midazolam and fentanyl were given for sedation and analgesia respectively, but additional agents could 
be used if sedation proved inadequate (propofol, methohexitone, gamma-hydroxybutyrate, ketamine or clonidine). The AER (midlatency $\mathrm{N}_{\mathrm{b}}$ peak) and corresponding level of sedation was recorded using five scoring systems [Ramsay, Cohen, Cambridge, Bloomsbury and Newcastle (Cook) Sedation Scores]. Kendall's correlation coefficients were calculated and regression analysis performed.

\section{Results}

The authors carried out 190 measurements in the 95 patients. Patients with higher APACHE II scores were more likely to be deeply sedated since, for example, severe acute respiratory distress syndrome (ARDS) patients required greater sedation to prevent ventilator dysynchrony and impaired gas exchange. The Ramsay score revealed the best correlation with changes in $\mathrm{N}_{\mathrm{b}}$ latency (see table)

\section{Table}

\begin{tabular}{|l|c|c|l|}
\hline Scoring system & Kendall's coefficient & Coefficient of determination $\left(\mathrm{r}^{2}\right)$ & $\boldsymbol{P}$ \\
\hline Ramsay & 0.71 & 0.68 & $<0.05$ \\
\hline Cohen & -0.62 & 0.56 & $<0.05$ \\
\hline Cambridge & 0.68 & 0.61 & $<0.05$ \\
\hline Bloomsbury & -0.62 & 0.57 & $<0.05$ \\
\hline Newcastle & -0.64 & 0.59 & $<0.05$ \\
\hline
\end{tabular}

However scatterplots showed a large variation of $\mathrm{N}_{b}$ latencies with deeper levels of sedation; ie these scoring systems are poor discriminators at deeper sedation levels.

\section{Discussion}

Derived electrophysiological measurements and evoked potentials have all been used to measure depth of sedation/anaesthesia but require training and experience to develop competency. However, since clinical scoring systems are poor discriminators at deeper sedation levels, the authors suggest that AERs may have a role where deeper levels of sedation are required for prolonged periods. It is postulated that the Ramsay score showed the best correlation since it includes a primitive reflex (glabellar tap) to discriminate asleep states. 


\section{References}

1. Schulte-Tamburen AM, Scheier J, Briegel J, Schwender D, Peter K: Comparison of five sedation scoring systems by means of auditory evoked potentials. Intensive Care Med. 1999, 25: 377-382.

This PDF file was created after publication. 